\title{
The effects of protective lung ventilation on regional cerebral oxygen saturation in intracranial tumor operation during dura opening: study protocol for a randomized controlled trial
}

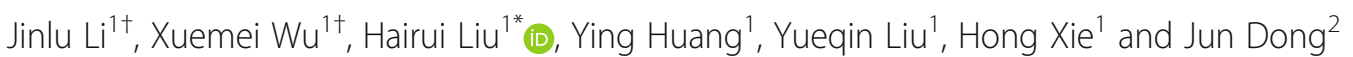

\begin{abstract}
Objective: The objective of this trial is to investigate the effects of protective lung ventilation on regional cerebral oxygen saturation $\left(\mathrm{rSO}_{2}\right)$ during dura opening, that is from Ta (after dura opening) to Tb (before dura closing), in patients undergoing intracranial tumor surgery.

Methods: This is a randomized controlled trial which will be carried out at the Second Affiliated Hospital of Soochow University. Fifty-four patients undergoing intracranial tumor surgery will be randomly allocated to the control group (C group) or the protective lung ventilation group ( $P$ group). In the $C$ group, the tidal volume (VT) will be set at $8 \mathrm{ml} / \mathrm{kg}$ of predicted body weight, but positive end-expiratory pressure (PEEP) and recruitment maneuvers will not be used. In the P group, VT will be set at $6 \mathrm{ml} / \mathrm{kg}$ of predicted body weight combined with individualized PEEP during dura opening, while in other periods of general anesthesia, $V T$ will be set at $8 \mathrm{ml} / \mathrm{kg}$ of predicted body weight. The level of $\mathrm{rSO}_{2}$, partial pressures of oxygen and carbon dioxide, oxygenation index, lactic acid level in arterial blood, and mean arterial pressure will be compared before anesthesia (T0), before dura opening (T1), after dura closing (T2), and $24 \mathrm{~h}$ after surgery (T3). Lung ultrasound scores will be measured at T0 and T3. The degree of brain relaxation at $\mathrm{T} 1$ and $\mathrm{T} 2$ will be evaluated by the surgeon using the brain relaxation scale. The amount of vasoactive drugs used and blood loss will be recorded during surgery. The duration of operation and reoperation rate will be recorded. The primary outcome of this study is the changes in $\mathrm{rSO}_{2}$ within $24 \mathrm{~h}$ postoperatively.

Discussion: This study aims to determine whether protective lung ventilation during dura opening can improve $\mathrm{rSO}_{2}$ and the state of pulmonary ventilation in patients undergoing intracranial tumor surgery, and to investigate whether this strategy affects the degree of brain tissue swelling and the reoperation rate after operation. If our results are positive, this study will show that protective lung ventilation during dura opening can be used effectively and safely in neurosurgical patients undergoing craniotomy for tumor resection.
\end{abstract}

Trial registration: Chinese Clinical Trial Registry, ChiCTR1900025632. Registered on 3 September 2019. chictr.org.cn.

Keywords: Randomized controlled trial, Regional cerebral oxygen saturation, Lung ultrasound, Brain relaxation, Craniotomy

\footnotetext{
* Correspondence: hrhr218@163.com

${ }^{\dagger}$ Jinlu Li and Xuemei Wu contributed equally to this work.

${ }^{1}$ Department of Anesthesiology, The Second Affiliated Hospital of Soochow

University, 1055 Sanxiang Road, Suzhou 215004, Jiangsu, China

Full list of author information is available at the end of the article
}

(c) The Author(s). 2020 Open Access This article is distributed under the terms of the Creative Commons Attribution 4.0 International License (http://creativecommons.org/licenses/by/4.0/), which permits unrestricted use, distribution, and reproduction in any medium, provided you give appropriate credit to the original author(s) and the source, provide a link to the Creative Commons license, and indicate if changes were made. The Creative Commons Public Domain Dedication waiver (http://creativecommons.org/publicdomain/zero/1.0/) applies to the data made available in this article, unless otherwise stated. 


\section{Background}

With the development of society and the progress of science and technology, more and more people receive delicate and complex procedures such as neurosurgery. Almost all these patients are under general anesthesia, which is basically inseparable from mechanical ventilation. Of these patients, 15-20\% have different degrees of alveolar collapse at the bottom of the lung before operation, and this phenomenon could persist for several days after operation due to the influence of mechanical ventilation with endotracheal intubation. Pulmonary complications play an important role in death and disability in patients who have has general anesthesia [1-3]. Craniotomy always requires the patient to be under general anesthesia for a long time with prolonged mechanical ventilation, which leads to a higher risk of postoperative atelectasis and pulmonary infection $[4,5]$. Atelectasis and pulmonary infection can seriously affect pulmonary ventilation and even lead to severe hypoxemia. Moreover, the long time period of the brain operation is more likely to cause an imbalance of brain oxygen supply and consumption. This imbalance of brain oxygen supply and consumption may lead to deterioration of brain function, such as postoperative cognitive function [6]. Postoperative cognitive dysfunction (POCD) will lower the quality of life, increase mortality, and aggravate the financial and mental burden of patients.

Protective lung ventilation (PLV) strategies have been recognized by many anesthesiologists and are widely used in clinical anesthesia $[7,8]$. Relevant studies suggest that low tidal volume combined with positive end-expiratory pressure (PEEP) ventilation and alveolar recruitment maneuver (ARM) is the most widely used PLV strategy, and it can reduce lung volume damage and pulmonary barotrauma, improve pulmonary function, and decrease postoperative pulmonary complications [9]. Theoretically, low tidal volume prevents excessive alveolar expansion [10], and higher PEEP prevents pulmonary atelectasis [11]. However, gradually increased PEEP to the level of $20 \mathrm{~cm}$ $\mathrm{H}_{2} \mathrm{O}$ or even higher is often needed in traditional PLV strategies $[5,9]$ which will obviously affect the circulation and intracranial pressure (ICP) of patients [12] and may increase airway pressure and reduce cerebral venous reflux and intraoperative operating space, thus limiting its application in patients with craniotomy. In addition, anesthesiologists often use a single PEEP or pulmonary retention mode, ignoring individual differences among patients, thus affecting the effect of PLV [13, 14].

In recent years, with the development of medical monitoring equipment, regional cerebral oxygen saturation $\left(\mathrm{rSO}_{2}\right)$ monitoring technology $[15,16]$ has been gradually developed and used in clinical anesthesia. It provides a condition for real-time monitoring of the perfusion level of brain tissue in patients undergoing craniotomy and provides technical support for carrying out clinical research on protective pulmonary ventilation during craniotomy.

Near infrared spectrometry (NIRS) using near infrared technology is similar to pulse oxygen monitoring, which is commonly used. Near infrared light with a wavelength of $650-1100 \mathrm{~nm}$ has a good penetrability to human tissues such as scalp, skull, and brain, even up to several centimeters. The major color base (hemoglobin, $\mathrm{Hb}$ ) attenuated in the intracranial area of NIR light results in changes in the light intensity of penetrating human tissues. The oxygenation of brain tissues is evaluated by measuring the changes in the absorption spectrum, which are accompanied with changes in oxygenation state [17].

Up to the present, in consideration of the risks associated with PEEP and recruitment maneuvers, there are no correlative randomized controlled trials to explore the efficacy and safety of intraoperative pulmonary protective ventilation strategies in patients undergoing craniotomy. However, due to the disappearance of ICP after the dura opening during craniotomy, an individualized protective pulmonary ventilation strategy may avoid adverse effects on cerebral perfusion. The purpose of this study is to evaluate the effects of PLV strategies with individualized PEEP during dura opening on $\mathrm{rSO}_{2}$ in patients undergoing intracranial tumor surgery. Other outcomes include intraoperative brain relaxation, lung ultrasound scores $24 \mathrm{~h}$ after surgery, the reoperation rate within 1 week after operation, the amount of blood loss, and dosage of vasoactive drugs during surgery.

\section{Methods}

\section{Study design}

This is a single-center, randomized controlled trial which is being conducted at the Second Affiliated Hospital of Soochow University. Recruitment began on 3 September 2019. All patients eligible for inclusion will be recruited continuously until recruitment completion. The schedule of enrollment, interventions, and assessments is shown in Fig. 1. The basic information of patients will be as shown in Table 1 . The Standard Protocol Items: Recommendations for Interventional Trials (SPIRIT) checklist is provided as Additional file 1.

Patients will be randomized after signed informed consent and confirmation of inclusion and exclusion criteria. Randomization will be conducted via a computergenerated age stratification randomized controlled table. Age stratification is according to (1) $18<$ younger $\leq 40$ years; (2) $40<$ elder $\leq 65$ years. Patients who meet the enrollment criteria will be randomly allocated to the control group (C group) or the PLV group (P group) 


\begin{tabular}{|c|c|c|c|c|c|c|c|c|c|}
\hline \multirow[b]{3}{*}{ TIMEPOINT ${ }^{\star *}$} & \multicolumn{9}{|c|}{ STUDY PERIOD } \\
\hline & \multirow{2}{*}{$\begin{array}{c}\text { Enrolment } \\
-1 \text { day }\end{array}$} & \multirow{2}{*}{$\begin{array}{l}\text { Allocation } \\
\text { Surgery day }\end{array}$} & \multicolumn{7}{|c|}{ Post-allocation } \\
\hline & & & TO & $T 1$ & $T a$ & $T b$ & $T 2$ & $T 3$ & 7 day \\
\hline \multirow{4}{*}{$\begin{array}{r}\text { ENROLMENT: } \\
\text { Eligibility screen } \\
\text { Informed consent } \\
\text { Random allocation }\end{array}$} & & & & & & & & & \\
\hline & $\mathrm{x}$ & & & & & & & & \\
\hline & $\mathrm{x}$ & & & & & & & & \\
\hline & & $\mathrm{x}$ & & & & & & & \\
\hline \multicolumn{10}{|l|}{ INTERVENTIONS: } \\
\hline \multicolumn{10}{|l|}{ the control group } \\
\hline $\begin{array}{r}\text { the protective } \\
\text { ventilation group }\end{array}$ & & & & & $\mathrm{x}$ & $x$ & & & \\
\hline \multicolumn{10}{|l|}{ ASSESSMENTS: } \\
\hline $\begin{array}{l}\text { Regional cerebral } \\
\text { oxygen saturation }\end{array}$ & & & $\mathrm{x}$ & $x$ & & & $x$ & $x$ & \\
\hline $\begin{array}{r}\text { Partial pressure of } \\
\text { oxygen }\end{array}$ & & & $x$ & $x$ & & & $x$ & $\mathrm{x}$ & \\
\hline $\begin{array}{l}\text { Partial pressure of } \\
\text { carbon dioxide }\end{array}$ & & & $x$ & $\mathrm{x}$ & & & $x$ & $\mathrm{x}$ & \\
\hline Oxygenation index & & & $x$ & $x$ & & & $x$ & $x$ & \\
\hline Lactic acid & & & $\mathrm{x}$ & $x$ & & & $x$ & $x$ & \\
\hline $\begin{array}{r}\text { Mean arterial } \\
\text { pressure }\end{array}$ & & & $x$ & $x$ & & & $x$ & $x$ & \\
\hline $\begin{array}{r}\text { Lung ultrasound } \\
\text { score }\end{array}$ & & & $x$ & & & & & $x$ & \\
\hline $\begin{array}{c}\text { The amount of } \\
\text { vasoactive drugs }\end{array}$ & & & & & & & $x$ & & \\
\hline Blood loss & & & & & & & $x$ & & \\
\hline Brain relaxation & & & & $\mathrm{x}$ & & & $x$ & & \\
\hline $\begin{array}{c}\text { The secondary } \\
\text { operation rate }\end{array}$ & & & & & & & & & $x$ \\
\hline
\end{tabular}

Tb:Before dura closing;T2:After dura closing; T3:24h after surgery.

Fig. 1 Schedule of enrollment, interventions, and assessments

within $24 \mathrm{~h}$ before surgery. The allocation ratio is $1: 1$. Permuted randomization will be used and stratified by age. The designated staff will perform the allocation sequence. The designated staff assistants will assign participants to the interventions. This research staff will implement the allocation sequence through sealed, opaque, and stapled envelopes. Corresponding envelopes will not be opened until the enrolled participants complete the trial. The anesthesiologist who is

Table 1 Patient characteristics and baseline data

\begin{tabular}{|c|c|c|}
\hline Characteristic & C group & P group \\
\hline \multicolumn{3}{|l|}{ Male/female } \\
\hline \multicolumn{3}{|l|}{ Age, years } \\
\hline \multicolumn{3}{|l|}{ Body mass index (BMI), $\mathrm{kg} / \mathrm{m}^{2}$} \\
\hline \multicolumn{3}{|l|}{ Predicted body weight, kg } \\
\hline $\begin{array}{l}\text { American Society of Anesthesiologists } \\
\text { (ASA) physical status, I/II }\end{array}$ & & \\
\hline
\end{tabular}

responsible for the anesthesia implementation will know the grouping but will not participate in the follow-up visit. However, the neurosurgeon who evaluates brain relaxation will be blinded to the group allocation. The patients and the outcome assessor are all blinded to the grouping.

\section{Selection and withdrawal of participants Recruitment}

Participants will be recruited from the neurosurgical wards and identified by their presence on surgical lists. The investigator informs the participant or the participant's legal representative of all aspects. The study intervention will be completed immediately after the surgery, but follow-up visits will extend to 1 week after surgery. The medical records will be reviewed following hospital discharge for in-hospital complications and medication usage. 


\section{Inclusion criteria}

Patients will be included if they fulfill all of the following criteria:

1. Patients scheduled to receive elective intracranial primary tumor resection who are aged between 18 and 65 years old

2. The maximum diameter of the tumor is $2-5 \mathrm{~cm}$ (magnetic resonance imaging, MRI)

3. American Society of Anesthesiologists (ASA) classification I-II

4. $18.5<$ body mass index $(\mathrm{BMI})<28$

5. Glasgow Coma Scale score of more than 8 points.

\section{Exclusion criteria}

Patients will be excluded if they have any of the following criteria:

1. Patients with chronic lung disease, pulmonary infection, or other severe pulmonary complications such as acute respiratory failure

2. Patients with a history of pulmonary surgery

3. Patients with severe brain, heart, liver, or kidney diseases

4. Patients with nerve injury affecting preoperative breathing

5. Pregnant women

6. Those who refuse to participate in the research.

\section{Termination criteria}

The following will cause participants to be terminated from the study:

1. Duration of anesthesia $<4 \mathrm{~h}$ or $>8 \mathrm{~h}$, or duration of operation $<2 \mathrm{~h}$ or $>6 \mathrm{~h}$

2. Patients with significantly increased intraoperative ICP or swelling of brain tissue

3. Patients with intraoperative endotracheal catheter after surgery

4. Repeat intubation or operation within $24 \mathrm{~h}$ after operation.

\section{Study intervention}

\section{Related parameter setting during operation}

All patients will be randomly allocated to the $C$ group or the $\mathrm{P}$ group according to the computer-generated random number table. In the $\mathrm{C}$ group, tidal volume (VT) will be set at $8 \mathrm{ml} / \mathrm{kg}$ of predicted body weight, with PEEP $=0$, and recruitment maneuvers will not be used. The predicted body weight is calculated as follows: for men, $50+0.91$ (height in centimeters - 152.4); and for women, $45.5+0.91$ (height in centimeters - 152.4) [18]. In the $\mathrm{P}$ group, VT will be set at $6 \mathrm{ml} / \mathrm{kg}$ of predicted body weight combined with individualized PEEP during intraoperative dura mater opening $[6,7]$, but in other periods of general anesthesia, VT will be set at $8 \mathrm{ml} / \mathrm{kg}$ of predicted body weight. For the titration method of individualized PEEP [19], VT and respiratory rate will be fixed at $6 \mathrm{ml} / \mathrm{kg}$ and 15 beats per minute during PEEP trial. Titration can only begin once the dura is opened. The titration for the individual PEEP can then be initiated by increasing PEEP from 0 to $10 \mathrm{~cm} \mathrm{H}_{2} \mathrm{O}$ incrementally. Each PEEP level $\left(0,1,2,3,4,5,6,7,8,9,10 \mathrm{cmH}_{2} \mathrm{O}\right)$ will be maintained for $1 \mathrm{~min}$, and the pulmonary compliance of the last cycle will be recorded at each PEEP level. The PEEP value at the highest compliance will then be selected as the individual PEEP of the patient.

Peripheral venous access will be established after the patient enters the operating room. If necessary, central venous access will be established. Noninvasive blood pressure (NBP), electrocardiogram (ECG), heart rate (HR), oxygen saturation $\left(\mathrm{SpO}_{2}\right)$, and bispectral index (BIS) will be routinely monitored. Radial artery catheterization under local anesthesia will be used to monitor invasive arterial pressure and collect blood samples. All of the above data will be collected completely. Fentanyl $5 \mu \mathrm{g} / \mathrm{kg}$, etomidate 0.3 $\mathrm{mg} / \mathrm{kg}$, rocuronium $0.6 \mathrm{mg} / \mathrm{kg}$ will be used for induction and will be started after oxygen flow of $0.1 \mathrm{~L} / \mathrm{kg} / \mathrm{min}$ has been given by mask for $2 \mathrm{~min}$. Volume-controlled mechanical ventilation will be conducted with a Primus anesthesia machine (Dräger, Lübeck, Germany) after the endotracheal catheter is inserted to a correct position. The VT will be set at $8 \mathrm{ml} / \mathrm{kg}$ of predicted body weight, the inhalation oxygen fraction $\left(\mathrm{FiO}_{2}\right)$ will be set at 0.5 , the inhalation-expiration ratio (I:E) $=1: 2$, and the fresh gas flow will be set at $1 \mathrm{~L} / \mathrm{min}$. The respiration rate will be adjusted according to the result of end-expiratory carbon dioxide $\left(\mathrm{ETCO}_{2}\right)$, and the end-tidal $\mathrm{CO}_{2}$ pressure $\left(\mathrm{PetCO}_{2}\right)$ will be maintained between 30 and $35 \mathrm{mmHg}$. There will be $1 \%$ sevoflurane combined with propofol and remifentanil to maintain anesthesia, and the BIS value will be maintained at $45-55$. During the operation, intermittent injection of fentanyl and rocuronium will be used to deepen the anesthesia. Extubation indications are that patients are awake and cooperating and muscle relaxation monitoring train-of-four (TOF) stimulation > 90\% [20]. Intraoperative fluid intake and urine volume will be monitored closely. The level of $\mathrm{rSO}_{2}$ will be recorded in the tumor surgery area of the patients before anesthesia (T0), before dura opening (T1), after dura closing (T2), and 24 h after surgery (T3). Arterial blood of the patients will be collected for blood gas analysis. Lung ultrasound scores (LUSs) will be performed at T0 and T3. The degree of brain relaxation at $\mathrm{T} 1$ and $\mathrm{T} 2$ will be evaluated by the surgeon using the brain relaxation scale. The amounts of vasoactive drugs used and blood loss will be recorded during surgery. The duration of operation and reoperation rate will be recorded. 


\section{Study objective}

\section{Primary and secondary outcomes}

The primary outcome of this study is the changes in $\mathrm{rSO}_{2}$ within $24 \mathrm{~h}$ postoperatively. See Table 2 .

The secondary outcomes are as follows (the corresponding parameters are listed in Tables 2 and 3):

1. Changes between preoperative and postoperative LUSs in patients. LUSs will be used to evaluate postoperative atelectasis. The patient's chest is divided into 12 quadrants. Each of the 12 quadrants is assigned a score of 0 to 3 according to a modified grading system (Table 4). The LUS score (0-36) is then calculated by adding up the 12 individual quadrant scores, with higher scores indicating more severe atelectasis [21].

2. The mean arterial pressure changes during intraoperative pulmonary protective ventilation.

3. The partial pressures of oxygen $\left(\mathrm{PaO}_{2}\right)$ and carbon dioxide $\left(\mathrm{PaCO}_{2}\right)$, oxygenation index $(\mathrm{OI})$, and lactic acid level (Lac) in arterial blood changes during intraoperative pulmonary protective ventilation.

4. The amount of vasoactive drugs and blood loss will be compared in the two groups during surgery.

5. Intraoperative brain relaxation, which will be scored by the neurosurgeons after opening the cranium and before opening the dura. They will use a 4-point scale [22]: 1 , completely relaxed; 2 , satisfactorily relaxed; 3 , firm brain; 4 , bulging brain.

6. The secondary operation rate in 1 week after surgery (reoperation rate).

Table 2 Comparison of $\mathrm{rSO}_{2}, \mathrm{PaO}_{2}, \mathrm{PaCO}_{2}, \mathrm{Ol}, \mathrm{LaC}$, and MAP

\begin{tabular}{|c|c|c|c|c|c|}
\hline & & TO & $\mathrm{T} 1$ & $\mathrm{~T} 2$ & $\overline{T 3}$ \\
\hline \multirow[t]{2}{*}{$\mathrm{rSO}_{2}$} & C group & & & & \\
\hline & P group & & & & \\
\hline \multirow[t]{2}{*}{$\mathrm{PaO}_{2}$} & C group & & & & \\
\hline & P group & & & & \\
\hline \multirow[t]{2}{*}{$\mathrm{PaCO}_{2}$} & C group & & & & \\
\hline & P group & & & & \\
\hline \multirow[t]{2}{*}{ Ol } & C group & & & & \\
\hline & P group & & & & \\
\hline \multirow[t]{2}{*}{ Lac } & C group & & & & \\
\hline & P group & & & & \\
\hline \multirow[t]{2}{*}{ MAP } & C group & & & & \\
\hline & $P$ group & & & & \\
\hline
\end{tabular}

To before anesthesia, $T 1$ before dura opening, $T 2$ after dura closing, $T 324 \mathrm{~h}$ after surgery, $\mathrm{rSO}_{2}$ regional cerebral oxygen saturation, $\mathrm{PaO}_{2}$ partial pressure of oxygen, $\mathrm{PaCO}_{2}$ partial pressure of carbon dioxide, $\mathrm{Ol}$ oxygenation index, Lac lactic acid level, MAP mean arterial pressure
Table 3 Perioperative parameters

\begin{tabular}{l}
\hline C group \\
\hline Tidal volume, $\mathrm{ml}$ \\
Individual PEEP, $\mathrm{CmH}_{2} \mathrm{O}$ \\
Duration of anesthesia, min \\
Duration of operation, min \\
Duration of dura opening, min \\
Tumor size (maximum diameter) \\
Brain relaxation scale (T1) \\
Brain relaxation scale (T2) \\
Lung ultrasound score (T0) \\
Lung ultrasound score (T3) \\
Volume of total fluid, $\mathrm{ml}$ \\
Amount of bleeding, $\mathrm{ml}$ \\
Volume of urine, $\mathrm{ml}$ \\
Dosage of vasoactive agent, $\mathrm{mg}$ \\
Reoperation rates
\end{tabular}

\section{Reporting of adverse events}

All adverse events will be recorded and closely monitored until resolution or stabilization. In the event of any serious adverse event ( $\geq$ grade 3 ) [23], the event will be immediately reported to the Endpoint Adjudication Committee, which will determine the severity and causality of the adverse events. The chief investigator will be responsible for all adverse event reporting.

\section{Withdrawal from the trial}

We will consider patient withdrawal from the trial if the following conditions occur: (1) severe brain swelling during the operation; (2) the patient has a cough during surgery; (3) the patient has persistent hypotension and circulatory instability.

\section{Data collection and management}

All the patient information will be obtained through the electronic medical record system. The consent of the treating neurosurgeon, who will help us make the neurological diagnosis, will also be obtained. All personal information will be collected through the hospitalized medical records by a member of the research team and be kept strictly confidential for research purposes only. The research team members will be responsible for maintaining personal data. Only the primary investigator and the designated researcher can obtain interim results and final test data.

\section{Data Monitoring Committee}

The project will be monitored by a Data Monitoring Committee (DMC) composed of specialists in anesthesiology, ethics, statistics, and methodology. The DMC will audit through regular interviews or telephone calls. 
Table 4 Modified lung ultrasound scores

\begin{tabular}{lllll}
\hline Quotation & Normal aeration & Small loss of aeration & Moderate loss of aeration & Severe loss of aeration \\
& 0 & 1 & 2 & 3 \\
\hline Modified lung ultrasound score & $0-2$ B lines & $\geq 3$ B lines & Multiple coalescent B lines & Consolidation \\
& & OR & OR & OR \\
& & con multiple small subpleural & multiple small subpleural & small subpleural consolidation \\
& & consolidations separated by a & consolidations separated & of $>1 \times 2 \mathrm{~cm}$ in diameter \\
& normal pleural line & by a thickened or irregular & \\
& & pleural line & \\
\hline
\end{tabular}

Lung ultrasound scores can be calculated by adding up the 12 individual pulmonary quadrant scores yielding a score between 0 (no aeration loss) and 36 (complete aeration loss)

\section{Sample size and justification}

We calculated the sample size through the website http:// www.sample-size.net/sample-size-proportions/.

The difference in brain oxygen saturation before and after surgery was $3.6 \pm 4.1, \alpha=0.05, \beta=0.2$ [7]. Based on this, it can be calculated that the sample size required for our study is 44 cases. Considering a $20 \%$ shedding rate, a total of 53 participants $(44+44 * 20 \%)$ need to be recruited. Due to the 1:1 distribution ratio, a total of 54 cases will be recruited.

\section{Statistics}

The SPSS 19.0 software package for Windows (SPSS, Inc., Chicago, IL, USA) will be used for all statistical analyses. The quantitative variables will be expressed as mean \pm standard deviation (SD) or median (interquartile range [IQR]) and analyzed by using the analysis of variance (ANOVA) or Mann-Whitney $U$ test. Multiple comparisons among continuous variables at different time points will be performed using the Student-NewmanKeuls method for post hoc test. The incidence of reoperation rate will be expressed as the number of patients (percentage) and be analyzed by using the chi-square $\left(x^{2}\right)$ test. $P$ values $<0.05$ will be considered to be statistically significant. After the follow-up of half of the cases, the interim analysis will be conducted to evaluate the validity of the main results.

\section{Discussion}

This study is a single-center, randomized controlled trial exploring whether protective lung ventilation (PLV) during intraoperative dura opening can improve regional cerebral oxygen saturation $\left(\mathrm{rSO}_{2}\right)$ in neurosurgical patients.

The incidence of postoperative pulmonary complications (PPCs) is high due to the long mechanical ventilation in neurosurgery. Qaseem et al. [24] reported that the risk of PPCs increased when the operation time is more than $4 \mathrm{~h}$. The incidence of PPCs was $28.4 \%$ (20.2$37.9 \%$ ) in patients with neurosurgery lasting for longer than $300 \mathrm{~min}$ [25]. PEEP can lower the incidence of postoperative respiratory complications, prevent atelectasis, and reduce the risk of ventilators associated with lung injury.
In this study, individual PEEP $\left(<10 \mathrm{cmH}_{2} \mathrm{O}\right)$ will be used to avoid the effect of high PEEP on intracranial pressure (ICP). It is a crucial issue that PEEP can be safely used in craniotomy. Therefore, pulmonary protective ventilation will be performed during dura opening, and cerebral relaxation will be assessed before dura incision. If the ICP is elevated enough to affect the operation for using PEEP, we will abandon the case and change the ventilation parameters. The case will be reported to the principal investigator.

The $\mathrm{rSO}_{2}$ is actually the mixed oxygen saturation of local brain tissues, which can better reflect the change of brain oxygen supply and consumption balance during the perioperative period. Samra et al. [26] studied 100 patients who underwent carotid endarterectomy. They found that if the $\mathrm{rSO}_{2}$ value decreased by $20 \%$ compared with the baseline value after internal carotid artery occlusion, it predicted the possibility of neurological complications, and indicated that its sensitivity was $80 \%$ and its specificity was $82 \%$. Since the ratio of cerebral blood volume to arterial/venous blood flow is approximately 20:80, the NIRS value mainly represents cerebral venous oxygen saturation, which is completely unaffected by hypoxemia and hypocarbonemia, and better reflects the changes in the balance of oxygen supply and consumption in the brain [27]. Near infrared spectroscopy (NIRS) as a brain oxygen monitoring method has the following characteristics: it is continuous and noninvasive and convenient, and it has a high degree of sensitivity and specificity [28]. Monitoring $\mathrm{rSO}_{2}$ can detect changes of the cerebral blood flow and oxygen supply and consumption balance in the brain area as early as possible, and judge the degree of cerebral ischemia and hypoxia and changes in brain function. Timely adjustment of the anesthesia plan is helpful to guide perioperative anesthesia management, so as to prevent POCD, shorten the hospitalization period, and improve quality of life.

We focus on whether a pulmonary protective ventilation strategy can affect cerebral venous reflux and brain tissue oxygenation and, ultimately, the prognosis of patients. PLV after incision of the dura can reduce the returned blood volume that results in exposing potential bleeding spots, which is beneficial in helping the surgeon 
to stop bleeding. Due to the opening of the dura, the ICP disappears, and the decreased cerebral perfusion pressure caused by the expansion of the lung is improved.

This study is a prospective, randomized controlled trial. This study aims to investigate the effect of intraoperative pulmonary protective ventilation in neurosurgical craniotomy. If we are able to demonstrate the safety and effectiveness of intraoperative pulmonary protective ventilation with individualized PEEP during dura opening in neurosurgical craniotomy, it will improve the prognosis of patients undergoing neurosurgery and reduce medical costs.

\section{Trial status}

The study was registered on the registry website http:// chictr.org.cn/ with registration number ChiCTR1900025632 on 3 September 2019. The protocol version is 3.0, dated 3/ 9/2019. The study began on 3 September 2019, and the planned completion date will be September 2020. The trial status is currently recruiting. Recruitment began on 3 September 2019, and the planned recruitment completion date will be June 2020 .

\section{Supplementary information}

Supplementary information accompanies this paper at https://doi.org/10. 1186/s13063-019-4025-9.

Additional file 1. SPIRIT 2013 checklist: recommended items to address in a clinical trial protocol and related documents.

\section{Abbreviations}

ARM: Alveolar recruitment maneuver; BIS: Bispectral index; ECG: Electrocardiogram; $\mathrm{ETCO}_{2}$ : End-expiratory carbon dioxide; $\mathrm{FiO}_{2}$ : Oxygen fraction; HR: Heart rate; ICP: Intracranial pressure; Lac: Lactic acid level; MAP: Mean arterial pressure; NBP: Noninvasive blood pressure; NIRS: Near infrared spectrometer (spectrometry, spectroscopy); Ol: Oxygenation index; $\mathrm{PaCO}_{2}$ : Partial pressure of carbon dioxide; $\mathrm{PaO}_{2}$ : Partial pressure of oxygen; PEEP: Positive end-expiratory pressure; $\mathrm{PetCO}_{2}$ : End-tidal $\mathrm{CO}_{2}$ pressure; PLV: Protective lung ventilation; PPC: Postoperative pulmonary complication; $\mathrm{rSO}_{2}$ : Regional cerebral oxygen saturation; $\mathrm{SpO}_{2}$ : Oxygen saturation; $\mathrm{VT}$ : Tidal volume

\section{Acknowledgements}

Not applicable.

\begin{abstract}
Authors' contributions
HL conceived and designed the study, coordinates the overall study, and contributed to the final manuscript. JL conceived and designed the study, coordinates the overall study, and contributed to the final manuscript. XW participated in the design of the study and drafted the manuscript. YH and YL performed the sample size calculation, drafted the statistical analysis plan and collected the data. HX participated in the design of the study. JD conceived the study, and guided the calculation of the sample size and the plans of the statistical analysis. All authors read and approved the final manuscript.
\end{abstract}

\section{Authors' information}

Not applicable.

\section{Funding}

This study was not funded.

\section{Availability of data and materials}

The datasets analyzed during the current study are available from the corresponding author on reasonable request.

\section{Ethics approval and consent to participate}

The Ethics Committee of the Second Affiliated Hospital of Soochow University approved the study on November 23, 2018, with file number EC-AF (JD)-06/6.1, study protocol version 3.0. The study is designed in accordance with the principles of the Declaration of Helsinki. Written informed consent is obtained from every enrolled patient upon request by the review board.

\section{Consent for publication}

Not applicable.

\section{Competing interests}

The authors declare that they have no competing interests.

\section{Author details}

${ }^{1}$ Department of Anesthesiology, The Second Affiliated Hospital of Soochow University, 1055 Sanxiang Road, Suzhou 215004, Jiangsu, China. ${ }^{2}$ Department of Neurosurgery, The Second Affiliated Hospital of Soochow University, 1055 Sanxiang Road, Suzhou 215004, Jiangsu, China.

Received: 27 September 2019 Accepted: 21 December 2019

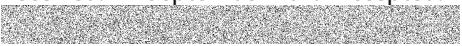

References

1. Sutherasan $Y$, Vargas M, Pelosi P. Protective mechanical ventilation in the non-injured lung: review and meta-analysis. Crit Care. 2014;18(2):1-12.

2. Fernandez-Bustamante A, et al. Postoperative pulmonary complications, early mortality, and hospital stay following noncardiothoracic surgery: a multicenter study by the Perioperative Research Network Investigators. JAMA Surg. 2017;152(2):157-66.

3. Finks JF, Osborne NH, Birkmeyer JD. Trends in hospital volume and operative mortality for high-risk surgery. N Engl J Med. 2011:364(22):2128-37.

4. Dasenbrock HH, Liu KX, Devine CA, et al. Length of hospital stay after craniotomy for tumor: a National Surgical Quality Improvement Program analysis. Neurosurg Focus. 2015;39(6):E12.

5. Kourbeti IS, Vakis AF, Ziakas P, et al. Infections in patients undergoing craniotomy risk factors associated with post-craniotomy meningitis. J Neurosurg. 2015;122(5):1113-9.

6. Kim J, et al. Postoperative cognitive dysfunction and the change of regional cerebral oxygen saturation in elderly patients undergoing spinal surgery. Anesth Analg. 2016;123(2):436-44.

7. Damian D, Esquenazi J, et al. Incidence, outcome, and risk factors for postoperative pulmonary complications in head and neck cancer surgery patients with free flap reconstructions. J Clin Anesth. 2016;28(2):12-8.

8. Mercado P, Maizel J, Kontar $L$, et al. Moderate and severe acute respiratory distress syndrome: hemodynamic and cardiac effects of an open lung strategy with recruitment maneuver analyzed using echocardiography. Crit Care Med. 2018;46(10):1608-16

9. Hew M, Tay TR. The efficacy of bedside chest ultrasound: from accuracy to outcomes. Eur Respir Rev. 2016;25(141):230-46.

10. Tojo $\mathrm{K}$, et al. Atelectasis causes alveolar hypoxia-induced inflammation during uneven mechanical ventilation in rats. Intensive Care Med Exp. 2015;3(1):56.

11. Chikhani $\mathrm{M}$, et al. High PEEP in acute respiratory distress syndrome: quantitative evaluation between improved arterial oxygenation and decreased oxygen delivery. Br J Anaesth. 2016;117(5):650-8.

12. Flexman AM, Gooderham PA, Griesdale DE, et al. Effects of an alveolar recruitment maneuver on subdural pressure, brain swelling, and mean arterial pressure in patients undergoing supratentorial tumour resection: a randomized crossover study. Can J Anaesth. 2017;64(3):626-33.

13. Pereira SM, Tucci MR, Morais CC, et al. Individual positive end-expiratory pressure settings optimize intraoperative mechanical ventilation and reduce postoperative atelectasis. Anesthesiology. 2018;129(6):1070-81.

14. Costa Leme A, et al. Effect of intensive vs moderate alveolar recruitment strategies added to lung-protective ventilation on postoperative pulmonary complications. JAMA. 2017:317(14):1422.

15. Venkateswaran P, Sriganesh $\mathrm{K}$, et al. Regional cerebral oxygen saturation changes after decompressive craniectomy for malignant cerebral venous thrombosis. J Neurosurg Anesthesiol. 2019;31(2):241-6. 
16. Jia Z, Teng Y, Liu Y, et al. Influence of high-flow modified ultrafiltration on brain oxygenation. Perfusion. 2018;33(3):203-8.

17. Zheng F, et al. Cerebral near-infrared spectroscopy monitoring and neurologic outcomes in adult cardiac surgery patients: a systematic review. Anesth Analg. 2013;116(3):663-76.

18. Treschan TA, Kaisers W, Schaefer MS, et al. Ventilation with low tidal volumes during upper abdominal surgery does not improve postoperative lung function. Br J Anaesth. 2012;109:263-71.

19. Park M, Ahn HJ, Kim JA, et al. Driving pressure during thoracic surgery: a randomized clinical trial. Anesthesiology. 2019;130(3):385-93.

20. Eriksson $\mathrm{LI}$, et al. Functional assessment of the pharynx at rest and during swallowing in partially paralyzed humans: simultaneous video manometry and mechanomyography of awake human volunteers. Anesthesiology. 1997;87(5):1035-43.

21. Monastesse A, Girard F, Massicotte N, et al. Lung ultrasonography for the assessment of perioperative atelectasis: a pilot feasibility study. Anesth Analg. 2017;124:494-504

22. Prabhakar H, Singh GP, Mahajan C, et al. Intravenous versus inhalational techniques for rapid emergence from anaesthesia in patients undergoing brain tumour surgery. Cochrane Database Syst Rev. 2016;9:CD010467.

23. National Cancer Institute. Common terminology criteria for adverse events. Version 4.0. 2009. https://evs.nci.nih.gov/ftp1/CTCAE/CTCAE_4.03/CTCAE_4. 03_2010-06-14_QuickReference_8.5x11.pdf.

24. Qaseem A, et al. Risk assessment for and strategies to reduce perioperative pulmonary complications for patients undergoing noncardiothoracic surgery: a guideline from the American College of Physicians. Ann Intern Med. 2006;144(8):575-80

25. Sogame $L C$, et al. Incidence and risk factors for postoperative pulmonary complications in elective intracranial surgery. J Neurosurg. 2008;109(2):222-7.

26. Samra SK, et al. Evaluation of a cerebral oximeter as a monitor of cerebral ischemia during carotid endarterectomy. Anesthesiology. 2000;93(4):964-70.

27. Plachky J, et al. Regional cerebral oxygen saturation is a sensitive marker of cerebral hypoperfusion during orthotopic liver transplantation. Anesth Analg. 2004;99(2):344-9.

28. Brogan RJ, Kontojannis V, Garara B, et al. Near-infrared spectroscopy (NIRS) to detect traumatic intracranial haematoma: a systematic review and metaanalysis. Brain Inj. 2017;31:581-8.

\section{Publisher's Note}

Springer Nature remains neutral with regard to jurisdictional claims in published maps and institutional affiliations.

Ready to submit your research? Choose BMC and benefit from:

- fast, convenient online submission

- thorough peer review by experienced researchers in your field

- rapid publication on acceptance

- support for research data, including large and complex data types

- gold Open Access which fosters wider collaboration and increased citations

- maximum visibility for your research: over $100 \mathrm{M}$ website views per year

At $\mathrm{BMC}$, research is always in progress.

Learn more biomedcentral.com/submissions 